\title{
On the Estimation of an Absolute Poverty Line:
}

\section{An Empirical Appraisal}

\section{Haroon Jamal}

The fad that different studies seeking to measure poverty in a given country often give differing results, although they apparently use the same method and same data source, has long disconcerted both experts in the field and the public in general. Such differences regarding poverty incidences reduce the credibility and technical reliability of these measurements, shed doubts on estimates of the level and evolution of poverty, and hinders inter-temporal comparisons. That is why it is important to foster greater consensus among researchers regarding the criteria and procedure to be used, with a view to progressing towards a common pattern, which will make the measurements more consistent and homogeneous, and guarantee their effective comparability. This policy paper provides a recommended strategy for estimating an absolute poverty line using household survey data of the years 1987-88, 1996-97 and 1998.

\section{Introduction}

What is poverty? Who are the poor? What are the ways of estimating its magnitude and depth? What are the ways of fighting it? We often tend to believe that these questions may be obvious or easily answered. But there are many views and several individuals who talk and write about poverty around the globe, without reaching an agreement as to what they are actually saying. Despite having a common basis, there are a variety of definitions and conceptions about poverty.

The variation in concepts reveals the multidimensional nature of poverty. The main operational emphasis however, remains on poverty as understood in terms of deprivation of food and other 'basic' commodities, and therefore, on private income or private consumption shortfalls.

For an aggregate or macro perspective of income poverty, various choices are available to estimate poverty in a given region or territory. In broad terms, it is possible to say that the debates generally start with the

\footnotetext{
* The author is Principal Economist at the Social Policy and Development Centre (SPDC), Karachi. The views expressed are those of the author and do not necessarily represent those of the SPDC.

This article was read as a paper at the $2^{\text {nd }}$ National Workshop on Poverty Analysis, Monitoring and Evaluation held at Bhurban in August 2002 under the auspices of Pakistan Institute of Development Economics and the World Bank Institute.
} 
diverse meanings, uses or functions, which the different authors attribute in their theorising on the concept of poverty. The diversion in estimates, as a result of using different methodologies and approaches, often creates confusion as to which estimate is more credible. Further evaluating poverty trends, which are important to inquire into the progress made on the poverty front, is difficult because of lack of consistency in adopting a specific methodology. The importance of the precise methodology in arriving at poverty estimates can be illustrated with the help of the following poverty incidences estimated from the 1996-97 Household Integrated Economic Survey (HIES) data.

Table 1: Percentage of Population Below Poverty Line Estimated from HIES 1996-97

\begin{tabular}{llll}
\hline Method and Approach Used By & Urban & Rural & Total \\
\hline 1. Amjad and Kamal & 42 & 27 & 32 \\
2. S. M. Jafri & 36 & 24 & 28 \\
3. Ercelawn & 53 & 29 & 36 \\
4. Social Policy and Development Center & 27 & 32 & 31 \\
5. Haris Gazdar & 21 & 38 & 33 \\
6. World Bank & - & - & 31 \\
\hline
\end{tabular}

The above table shows the different and diverse magnitude of poverty incidence, measured as a proportion of poor to the total population. Except Haris Gazdar (1994) and the World Bank (2001), other poverty estimates are based on a calorific approach with different methodology and calorie norms. Gazdar's estimation is based on the Basic Needs Approach. This figure was also adopted by the World Bank in its Pakistan Poverty Assessment (1995). To calculate the estimates for 1996-97, the poverty line used by Gazdar is adjusted using food and non-food Consumer Price Indices. The World Bank (2001) figure is taken from the World Development Report (2000/2001) and it is estimated using a 'dollar-a-day' poverty line. Other incidences are calculated employing the exact methodology used by the above authors to calculate the level of poverty.

The poverty incidence derived for 1996-97 as a whole ranges from 28 to 36 percent. Urban-rural breakdowns of poverty are similarly diverse. The situation portrayed above creates much confusion about the creditability of poverty estimates.

The level of poverty should provide a compelling signal for priorities in poverty-alleviation policies. Thus, the objective of this policy paper is to discuss 
various methodological options available for estimating the poverty line and to recommend a poverty criterion for national debate and consensus.

\section{Methodological Issues}

The breadth of the topic requires some selectivity. The focus of this paper therefore, is to only discuss the relevant methodological issues necessary to estimate a monetary poverty line from household survey data and to recommend a path to follow.

\section{Absolute and Relative Poverty}

For an aggregate or macro perspective of income poverty, absolute or relative approaches are the two alternative options available. Absolute poverty refers to subsistence below minimum, socially acceptable living conditions, usually established based on nutritional requirements and other essential goods. Relative poverty compares the lowest segments of a population with the upper segments, usually measured in income quintiles or deciles. Absolute and relative poverty trends may move in opposite directions. For example, relative poverty may decline while absolute poverty increases if the gap between the upper and lower strata of population is reduced by a decline in the well being of the former at the same time that additional households fall beneath the absolute poverty line.

Therefore, the choice of an 'absolute vs. relative' poverty criterion depends upon how one begins with either an emphasis on the extent of a shortfall in the standard of living or inequality as a source of poverty. If relatively perceived, poverty would appear to be primarily an aspect of inequality. In less developed countries (LDCs) where average levels of income are lower, this approach is relatively uncommon and less preferred. Many development planners place the highest priority on reducing absolute poverty because of the urgency associated with starvation, malnutrition and other afflictions. Most, if not all, studies for LDCs argue that poverty alleviation efforts need to be judged by their success not just in reducing inequality per se, but also in their impact upon absolute levels of welfare.

\section{Objective and Subjective Perspectives}

Poverty can be approached from objective or subjective perspectives. The objective perspective involves normative judgments as to what constitutes poverty and what is required to move people out of their impoverished slate. The subjective approach places a premium on people's preferences, on how much they value goods and services. Poverty 
measurement has traditionally been dominated by the objective approach. Only relatively recently has the international community as a whole taken a serious interest in measuring subjective poverty. This is mainly because of mounting recognition of the limitations associated with so-called objective indicators and the value of understanding the perspectives of the poor in shaping policies and programmes. Clearly, both objective and subjective perspectives bring valuable insights to the measurements and analysis of poverty. Economists however have traditionally based their work on the objective approach, mainly because of the obstacles encountered when trying to aggregate multiple individual (subjective) utilities across a population.

\section{How to Define Objective Absolute Needs}

It is, however, difficult to translate absolute needs into a poverty criterion. Defining the scope of basic needs and their minimum levels remain an area of controversy. Most studies for LDCs use food adequacy or nutritional (calorie) requirements as a criterion to define poverty levels.

The alternative option is to take the poverty line as the cost of achieving a minimum bundle of basic household requirements or needs. A first attempt was made by Ahmad (1993) in the context of Pakistan. With the help of consultative exercises and opinion surveys, he arrived at the quantum and value of various components of basic needs separately for urban and rural areas. This approach was also used by Gazdar et al (1994) after some modification.

A commonly used poverty line for measuring progress in reducing poverty worldwide is the 'dollar-a-day' measure introduced in the World Development Report (1990). This poverty line is expressed in 1985 purchasing power parity (PPP) and refers to household expenditure per capita. This measure has several well-known deficiencies. It does not allow for cost-of-living differentials within countries (rural/urban, provincial) and also does not distinguish between transient and chronic poverty (depth and severity). It is argued that a national poverty line is necessary for all policy purposes.

Therefore, the main choice to be made is between the calorie-based and basic-needs approach in setting the poverty line. Economists in most LDCs take the position that malnutrition must have a central place in the conception of poverty and thus, food adequacy should be given the highest priority among basic needs. This captures only one aspect of the idea of poverty, no doubt an important aspect. It then follows that a food adequacy 
standard of welfare would be the most useful approach to an aggregate criterion for absolute poverty.

The drawback with the second approach is the difficulty of interpreting the word 'basic' or 'sufficient'. Further, the second approach, which is based on express evaluations of social status, has been criticised on the grounds that it is arbitrary and subjective. Therefore the approach that shows the revealed behavior (based on actual consumption) should be the preferred approach.

\section{Calorie Norms}

To specify minimum calorie requirement is also not problem free. It is well known that calorie requirements vary between persons not only by sex and age, but also with climatic, work and living environments. Except for age and sex, the data is not rich enough to provide detailed information about a person's precise physiological condition of quantify a normal level of physical exertion. The conclusion that may be drawn therefore, is that the nutritional standard may depict a partial rather than complete picture of poverty.

By far the most common approach has been to use 2550 calories per day per adult (for urban as well as rural) as the calorific cut-off point. This calorie norm was recommended by the Pakistan Planning Commission and further supplemented by recommendations of the Food and Agriculture Organization (FAO) and World Health Organization (WHO).

As the rural lifestyle in general requires a greater consumption on calories than the urban lifestyle, than for any given level of income, rural households are likely to consume more calories, on average, than their urban counterparts. Therefore, it is argued that estimating the poverty line from a calorie-expenditure function using a unique caloric standard for the urban and- rural sub-sample would have the effect of over-estimating the urban poverty line in comparison with the rural.

A Working Group on Poverty Alleviation was formed in 1997 (GOP, 1997). The Group recommended 2550 and 2230 calorie requirements for rural and urban areas respectively.

The different calorie cut-off points for urban and rural are necessary in order to obtain reasonable estimations, but justifications in the difference in magnitude are not reported in the Working Group document. 
Often the difference is based on a judgement on the part of the analyst in order to produce 'plausible' rural and urban estimates of poverty. Similar 'plausibility' may be induced in the case of national poverty line adjustments. The calorific approach has, therefore the appearance of 'objectivity' while relying, ultimately, on reasonable but subjective judgement in order to arrive at results that are 'plausible'.

The problem in specifying calorie requirements and the consequent ambiguity or arbitrariness should not be overlooked. It is highly recommended to adhere to a cutoff point, whatever it may be, for intertemporal changes in poverty and the poverty line. This paper follows the Planning Commission recommendation of 2550 and 2230 calories per day per adult for rural and urban areas respectively.

\section{Deprivation and Lack of Capability to Acquire Adequate Calories}

Having arrived at nutritional norms, the next step is to translate these norms into monetary terms. Here, a number of options are available. To begin with, one possible capacity criterion would be in the form of the 'hypothetical' or 'typical' expenditure corresponding to requirements. Clearly there is a distinction between undernourished and being unable to avoid undernourishment. The latter concept is the most relevant one for public policy. For this exercise, calorie norms are translated by estimating the calorie-consumption functions.

Now poverty may be defined as the inability to obtain calorie requirements. Two choices are available to establish a relationship between calorie intake and household ability to acquire it. One could derive the food expenditure criterion from the calorie-expenditure relationship. But ignoring non-food expenditure may not be justified on various grounds. Very low non-food consumption, for instance, means that food expenditure could become highly vulnerable to even a small decrease in income. Therefore, a safety-margin in the poverty criterion is necessary to obtain a cut-off point, which may afford the critical expenditure necessary to acquire the usual means of subsistence. It is more or less a consensus among researchers and analysts to use non-durable expenditure (economic capacity) in the calorieexpenditure relationship for an upward adjustment to minimum food expenditure.

Poverty can then be used to define the poor by total expenditure falling short of the poverty line by the average dietary pattern and the expenditure would translate into fewer calories than required. 


\section{Consumption or Income as a Welfare Indicator}

The next issue is to map the poverty line to household income or consumption. Most studies on poverty in Pakistan have used total expenditure as the capacity to meet the poverty criterion. The authors usually cite data considerations, such as understatement of income or prefer expenditure, since its relative stability over time is considered as a reflection of 'permanent' income. However, Ercelawn (1991) argued that similar understatements in expenditure are also possible and, more importantly, subsistence expenditure may well involve quasi-permanent indebtedness.

Armed with the argument, which draws attention to the fact that in an economy where most of the economically active population are not in salaried remuneration but are either self-employed or work in farms or other family business, the reporting of consumption expenditure is likely to be more reliable than that of income. Hence household consumption as a primary poverty criterion is preferred in this research.

\section{Estimation of Poverty Line}

The before mentioned discussion regarding the choices and preferences for defining and estimating the poverty line is recapitulated in Chart 1. This section provides details of actual computation of the poverty line from Household Integrated Economic Survey of 1987-88, 1996-97 and 1998-99. Similar methodology is applied to these household surveys.

\section{Calorie Norm Conversion}

In order to ease interpretation and also for specification of calorieconsumption function (CCF), minimum calorie requirements are converted into per capita term using household demographic data. Food Consumption Tables for Pakistan (2001) provide the recommended daily allowance for the Pakistani population for various age and sex compositions. These requirements are used to convert daily allowance from adult equivalent to per capita terms.

\section{Estimation of Calorie-Consumption Functions}

Having considered other options, it is preferred to estimate national calorie-consumption function separately for urban and rural areas. It is argued that consumption behaviour, purchasing patterns, dietary habits, taste, ecology etc., are extremely different for urban and rural groups, and simple inclusion of a dummy variable in the function would not give an accurate picture. A similar argument is true, to a lesser extent, in the case 
of the provinces. However, a separate province-wise estimation of function is not statistically recommended due to the small sample problem. It was also decided to estimate CCF from the lower quartile of distribution after ranking households by per capita expenditure.

The results of the estimated functions are displayed in Table 2 through Table 4. Daily calorie consumption is regressed on non-durable expenditure (excluding taxes). The functional forms are chosen on the basis of maximisation of $\mathrm{R}^{2}$ criterion. Nonetheless, other statistical tests are also applied before choosing the functional form.

Table 5 presents the estimated poverty lines from these data sets. As separate calorie-consumption functions are estimated for urban and rural areas, direct estimation of the national poverty line is not possible. A population weighted average poverty line, however, turns out as Rs. 206, Rs. 555 and Rs. 605 per capita per month in 1988, 1997 and 1999 prices respectively.

Table 2: Estimated Calorie-Consumption Functions (1987-88)

\begin{tabular}{lllll}
\hline & $\begin{array}{l}\text { Estimated } \\
\text { Coefficients }\end{array}$ & T-Value & $\mathbf{R}^{2}$ & F-Value \\
\hline Urban Areas & & & 0.12 & 47.8 \\
$\begin{array}{l}\text { Dependent Variable } \\
\text { Log (Per Capita Calorie }\end{array}$ & & & \\
Consumption) & & & & \\
(Constant) & 6.875 & 178.94 & & \\
Per Capita Expenditure & 0.003 & 13.09 & & \\
Dummy Variable for Sindh & -0.043 & -2.52 & & \\
Dummy Variable for NWFP & 0.018 & 1.019 & & \\
Dummy Variable for Balochistan & 0.062 & 2.059 & & 57.4 \\
Rural Areas & & & 0.13 & \\
Dependent Variable & & & & \\
Log (Per Capita Calorie & & & & \\
Consumption). & & & & \\
(Constant) & 6.918 & 178.17 & & \\
Per Capita Expenditure & 0.004 & 14.08 & & \\
Dummy variable for Sindh & 0.025 & 1.39 & & \\
Dummy Variable for NWFP & -0.042 & $-2,19$ & & \\
Dummy Variable for Baluchistan & -0.094 & -3.33 & & \\
\hline
\end{tabular}


Table 3: Estimated Calorie-Consumption Functions (1996-97)

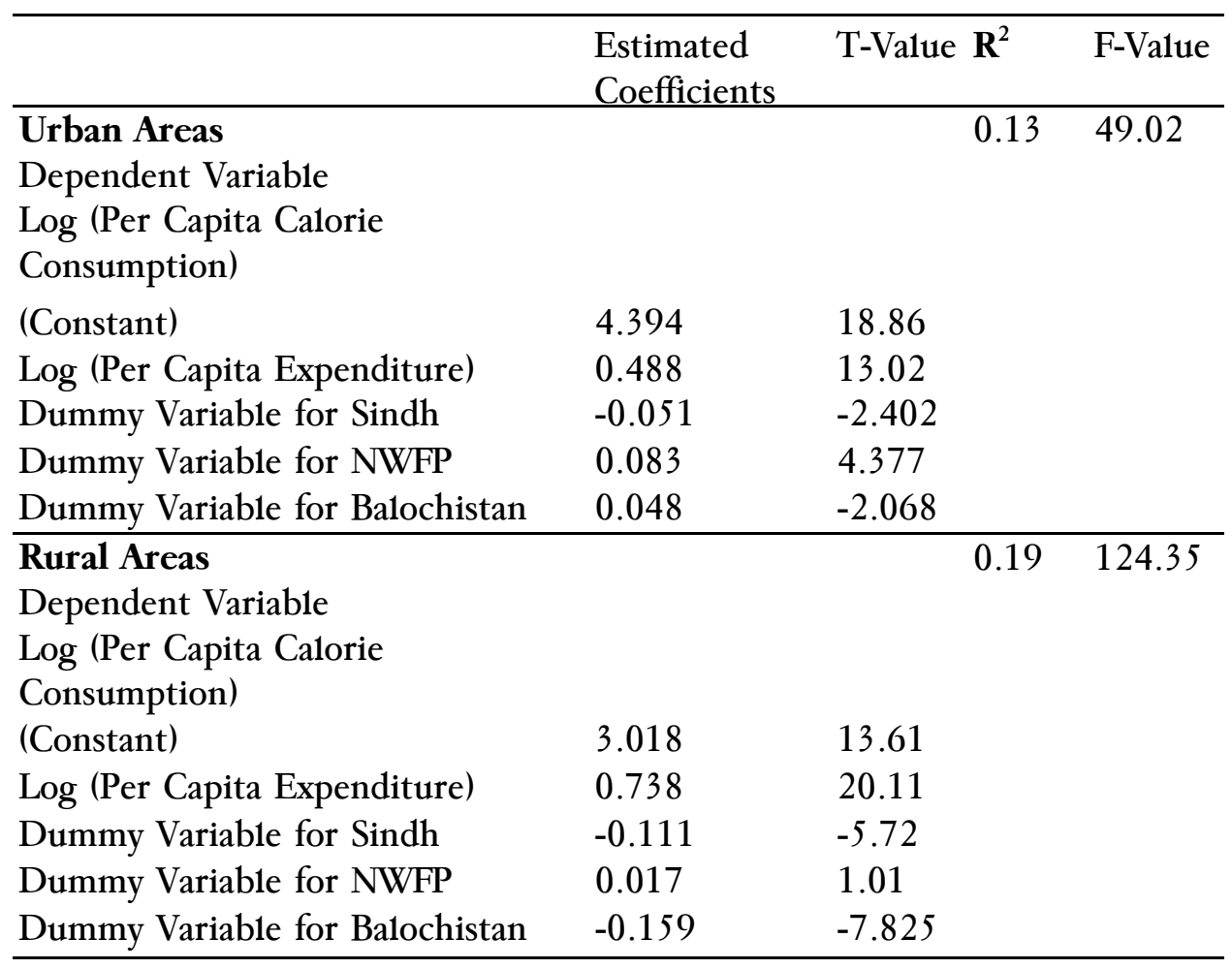


The Lahore Journal of Economics, Vol.7, No.2

Table 4: Estimated Calorie-Consumption Functions (1998-99)

\begin{tabular}{lllll}
\hline & $\begin{array}{l}\text { Estimated } \\
\text { Coefficient }\end{array}$ & T-Value & $\mathbf{R}^{2}$ & F-Value \\
\hline Urban Areas & & & 0.21 & 90.24 \\
$\begin{array}{l}\text { Dependent Variable } \\
\text { Log (Per Adult Caloric }\end{array}$ & & & & \\
$\begin{array}{l}\text { Consumption) } \\
\text { (Constant) }\end{array}$ & 3.462 & 15.66 & & \\
Log (Per Adult Equivalent & 0.633 & 18.09 & & \\
Expenditure) & & & & \\
$\begin{array}{l}\text { Dummy variable for Sindh } \\
\text { Dummy Variable for NWFP }\end{array}$ & -0.136 & -5.67 & & \\
$\begin{array}{l}\text { Dummy Variable for } \\
\text { Baluchistan }\end{array}$ & 0.032 & 1.35 & & \\
\hline $\begin{array}{l}\text { Rural Areas } \\
\text { Dependent Variable }\end{array}$ & 0.026 & 0.91 & & \\
Log (Per Adult Calorie & & & & \\
Consumption) & & & & \\
(Constant) & & & & \\
Per Adult Equivalent & 6.927 & 262.00 & & \\
Expenditure & & & & \\
Dummy Variable for Sindh & 0.051 & -3.58 & & \\
Dummy Variable for NWFP & 0.033 & 2.05 & & \\
$\begin{array}{l}\text { Dummy Variable for } \\
\text { Balochistan }\end{array}$ & & & & \\
\hline
\end{tabular}

Table 5: Estimated Poverty Lines

\begin{tabular}{lrr}
\hline & Rural & Urban \\
\hline Per Day Calorie Requirements - Per Adult Equivalent Unit & 2550 & 2230 \\
Per Day Calorie Requirements - Per Capita (1987-88) & 2100 & 1862 \\
Per Day Calorie Requirements - Per Capita (1996-97) & 2090 & 1863 \\
Per Day Calorie Requirements - Per Capita (1998-99) & 2099 & 1873 \\
Poverty Line - Rupees Per Capita Per Month (1987-88) & 225 & 201 \\
Poverty Line - Rupees Per Capita Per Month (1996-97) & 528 & 618 \\
Poverty Line - Rupees Per Capita Per Month (1998-99) & 580 & 686 \\
\hline
\end{tabular}




\section{Poverty Aggregates}

Once a poverty line is defined, and hence the individual/household poverty status determined through relating the poverty line and household consumption, the question is how to aggregate this information into a single index to proxy the status of a group of individuals. The issues in this regard primarily relate to assigning weights to differing intensities of poverty (Foster et.al.,1984). The most popular measure, namely the Head-Count Index assigns equal weights to all poor regardless of the extent of poverty. There are several other measures, which have been suggested. These measures are sensitive to distribution among the poor. A class of functional forms, which has been suggested by Foster, Greer, and Thorbeke (FGT) uses various powers of the proportional gap between the observed and the required expenditure as the weights to indicate the level of intensity of poverty. The higher the power the greater the weight assigned to a given level of poverty. It therefore, combines both the incidence and intensity. The following formula is employed for measuring various poverty aggregates.

$\left.P^{\alpha}=(1 / N) \sum(Z-E X P) / Z\right]^{\alpha}$

Where;

$\mathrm{P}^{\alpha}=$ Aggregation measure

$\mathrm{N}=$ Total number of households

EXP $=$ Observed Household Expenditure

$\mathrm{Z}=$ Poverty Line

$\Sigma=$ Summation for all individuals who are below the poverty line

Putting $\alpha=0$, the formula shows the head count index (HCI), i.e., proportion of households whose consumption falls below the poverty line. This simple measure ignores the depth of poverty. Putting $\alpha=1$, the Proportionate Gap Index or Poverty Gap Index (PGI) is calculated. It measures the average distance from the poverty line. Although PGI shows the depth of poverty, it is insensitive to the distribution among the poor. Putting $\alpha=2$, the FGT2 index is calculated. The index takes into account inequality amongst the poor and shows the severity of poverty by assigning greater weights to those households who are far from the poverty line.

Table 6 displays various measures of poverty for 1987-88. The estimated poverty lines are mapped on household per capita total expenditure for computing these measures. Overall, 23 percent people were 
poor, according to the above definition of poverty and the poverty line. Rural incidence, depth and severity of poverty are high as compared with their urban counterpart. Table 7, which displays the magnitude of estimated poverty measures from HIES 1996-97, displays an increase of 5 percent in poverty incidence. The table also confirms a relatively high increase in urban poverty during these years.

Table 6: Estimates of Poverty Measures, 1987-88

(Percent of Poor Individuals)

\begin{tabular}{llll}
\hline & $\begin{array}{l}\text { Head Count Index } \\
\text { (Incidence) }\end{array}$ & $\begin{array}{l}\text { Poverty Gap Index } \\
\text { (Depth) }\end{array}$ & $\begin{array}{l}\text { FGT2 Index } \\
\text { (Severity) }\end{array}$ \\
\hline Pakistan & 23 & 4.41 & 1.26 \\
Urban & 19 & 3.50 & 1.00 \\
Rural & 26 & 4.79 & 1.38 \\
Estimated from HIES (1987-88) & & \\
\hline
\end{tabular}

Table 7: Estimates of Poverty Measures, 1996-97 (Percent of Poor Individuals)

\begin{tabular}{llll}
\hline & $\begin{array}{l}\text { Head Count } \\
\text { Index [Incidence] }\end{array}$ & $\begin{array}{l}\text { Poverty Gap Index } \\
\text { [Depth] }\end{array}$ & $\begin{array}{l}\text { FGT2 Index } \\
\text { [Severity] }\end{array}$ \\
\hline Pakistan & 28 & 5.54 & 1.67 \\
Urban & 25 & 4.95 & 1.51 \\
Rural & 30 & 5.80 & 1.74 \\
Estimated from HIES (1996-97) & & \\
\hline
\end{tabular}

Table 8 displays the magnitude of estimated poverty measures from 1998-99 HIES data. Few observations emerge quickly from the table. A sharp increase in the rural incidence is evident. The depth and severity of poverty have also increased noticeably during the period of three years, especially in the rural areas. No change in the poverty incidence in urban areas is observed. 
Table 8: Estimates of Poverty Measures, 1998-99 (Percent of Poor Individuals)

\begin{tabular}{llll}
\hline & $\begin{array}{l}\text { Head Count } \\
\text { Index }\end{array}$ & $\begin{array}{l}\text { Poverty Gap } \\
\text { Index [Depth] }\end{array}$ & $\begin{array}{l}\text { FGT2 Index } \\
\text { [Severity] }\end{array}$ \\
\hline Pakistan & 30 & 6.54 & 2.14 \\
Urban & 25 & 5.65 & 1.85 \\
Rural & 32 & 6.91 & 2.26 \\
Estimated from HIES (1998-99) & & \\
\hline
\end{tabular}

\section{Concluding Remarks}

The vast differences regarding the poverty incidences in a particular year reduce the credibility and technical reliability of the measurements, and hinder inter-temporal comparisons. It is, therefore, important to foster greater consensus among researchers regarding the criteria and procedure to be used, with a view to progressing towards a common pattern which will make the measurements more consistent and homogeneous, and guarantee their effective comparability.

This paper has suggested a recommended path or has set poverty criteria that are based upon nutritional norms and current relationship between diets and household expenditure. A step-by-step procedure is illustrated and applied for estimating the absolute poverty line using household survey data of HIES, 1987-88, 1996-97 and 1998-99. It is hoped that the paper can provide a base to achieve national consensus on this important issue.

The re-estimation of the poverty line for every year or for every new HIES data is not recommended due to operational implications. It is suggested to adopt a national (rural, urban) poverty line, at least for ten years for monitoring the impact of growth and poverty alleviation policies. Poverty measures from new available data may be computed by adjusting the national poverty line, either by CPI or by indexing price differentials between two consequent household surveys. 


\section{References}

Ahmad, M. 1993. Choice of a Norm of Poverty Threshold and Extent of Poverty in Pakistan, 1979-84, mimeo, Ministry of Finance, Islamabad.

Amjad , R and Kemal, A. R. 1997 Macroeconomic Policies and their Impact on Poverty Alleviation in Pakistan, The Pakistan Development Review, Vol. 36(1).

Ercclawn, A. 1991 Absolute Poverty as Risk to Hunger, mimeo, Applied Economics Research Centre.

Ercelawn, A. 1992. "Absolute Poverty in the 80's - Rural and Urban Trends in Pakistan ", Applied Economics Research Centre, Discussion Paper No. 161.

Foster, J.E., J. Greer, and E. Thorbecke, 1984. "A Class of Decomposable Poverty Measures", Econometrica, 52, pp. 761-66.

Gazdar, H et al 1994, "Recent Trends in Poverty in Pakistan", mimeo, London School of Economics,

Gazdar. H 1998. "Review of Pakistan Poverty Data", mimeo, Department of International Development, London.

Government of Pakistan 2001. "Food Consumption Table For Pakistan", Department of Agricultural Chemistry, NWFP Agriculture University, Peshawar.

Government of Pakistan 1997. "Overcoming Poverty: Report of the Task Force on Poverty Alleviation".

Jafri, S. M. 1999. "Assessing Poverty in Pakistan" In A Profile of Poverty in Pakistan, by Mahbubul Haq Centre for Human Development and United Nation Dcvelopment Program, Islamabad.

Malik, M. H. 1.988. "Some New Evidence on the Incidence of Poverty in Pakistan", Pakistan Development Review, 27(4).

Qureshi, S. K. and Arif, G. M. 1999. "Profile of Poverty in Pakistan. 199899", mimeo, Pakistan Institute of Development Economics. 
Social Policy and Development Centre 2000. Incidence of Income Poverty in Pakistan, Research Report No. 39

Social Policy and Development Centre 2000. Social Development in Pakistan, Annual Review - 2000, Oxford University Press, Karachi.

World Bank 2001. World Development Report -2000/2001, Washington DC, USA 